\title{
sciendo \\ AN ALGORITHM FOR DIAGNOSING INJECTION SYSTEMS OF MARINE ENGINES
}

DOI 10.2478/ntpe-2018-0029

\author{
DSc. PhD. Eng. Artur Bejger \\ PhD. Eng. Jan Drzewieniecki \\ Maritime University of Szczecin, Poland
}

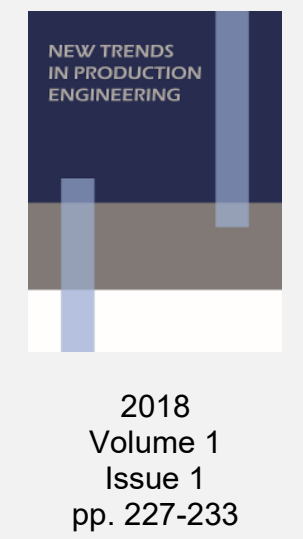

\begin{abstract}
The article presents the developed methods for diagnosing and analysing signals from injection systems of marine engines. As a source signal, the authors use elastic waves of acoustic emission. The essential fact in the case here considered is that the high frequency of signal from working elements of the injection system comes from a close source directly related to the change of the working parameters of the element (system). Characteristically for elastic waves of acoustic emission, low frequencies (e.g. those from other sources, such as machines in the engine room) are in this case attenuated. Therefore, the proper selection of the method for the analysis allows us accurately diagnose the injection system of a working engine.
\end{abstract}

Keywords: Diesel Engine, injection system, diagnosis, acoustic emission, elastic waves

\section{INTRODUCTION}

The combustion process is the basic phenomenon in the combustion engine and when it runs smoothly, it directly affects the power generated by the engine, level of environmental pollution, reliability of engine components, the cost effectiveness and operational safety (Deja, 2013; Wik 2010). The process of combustion largely depends on the technical condition of engine components and the process of fuel injection, so the analysis of these two processes is the basic tool for assessing the technical condition and correct adjustment of components of modern marine engines.

In actual operation of machines, it often occurs that to identify their technical condition, it is not necessary to know the extent of damage to a specific element; the user only has to determine whether the given machine works in the permitted range, i.e. the limit values are not exceeded. There is no need to identify a specific fault, but only to apply a simple bi-state measure of reliability: element is operational or faulty (good or bad).

The basic problem arising in the classical use of vibration measurement is a low value of signalto-noise ratio (SNR). High frequencies of waves generated in the form of acoustic emission significantly improve this measure of signal.

This paper follows previous publications of the authors (Bejger, 2016; Chybowski \& Gawdzinska, 2016; Mazuruk, 2013), offering a complete original method for diagnosing diesel engine's fuel injection systems, accordance with the requirements, which has also been submitted as a patent application (Bejger, 2016). In the literature there are no reported methods of similar capabilities. The authors use elastic waves of acoustic emission for diagnostic purposes. By definition, acoustic emission (AE) is a spontaneous generation of elastic waves related to a local dynamic change in material structure or, under the influence of external causes, changing the state of elastic energy acquired during operation (or process) (Saban Ulus and Selcuk Erkaya (2016). These waves are related to and depend on many physical processes occurring inside and on the surface of a material at nano-, micro-, or macroscopic level (Bejger, 2012; Holroyd, 2000; Mazuruk, 2013). During these processes, part of accumulated energy can be radiated as elastic waves. The acoustic emission as propagating elastic waves, owing to high frequency, forms a specific filter. The signal reaches the sensor, therefore its origin is relatively close to the examined process (fault); the other signals are attenuated. Machines installed on ships or other 
offshore objects are difficult to be diagnosed by traditional methods. A ship or drilling rig make up a system where all machines and devices are mounted on foundation within one whole structure. Therefore, the use of typical vibro-acoustic diagnostic methods is difficult in such an environment. $\mathrm{AE}$ elastic waves, due to their wave nature and the relation between attenuation and distance from the signal source, may be successfully used for diagnosing shipboard machines.

\section{INJECTION SYSTEM TESTS}

AE sensors detect mechanical movements or stress waves, and convert them into an electrical signal. The AE method is the most sensitive monitoring technique for early fault detection in rotating machine elements, especially in today's industry.

In terms of diagnosis, it is essential that recording and measurement of $A E$ signals take place at a strictly defined point. The authors demonstrated in their research that in the case of the injection system of a compression ignition engine the most relevant signal from diagnostic point of view is the one measured on the fuel discharge tube of the injection pump, on the injection pump body and at the connection of the injection tube with the injector (Fig. 1). The sensor position choice (one of the three mentioned) depends on which component is to be accurately diagnosed: injector or injection pump.

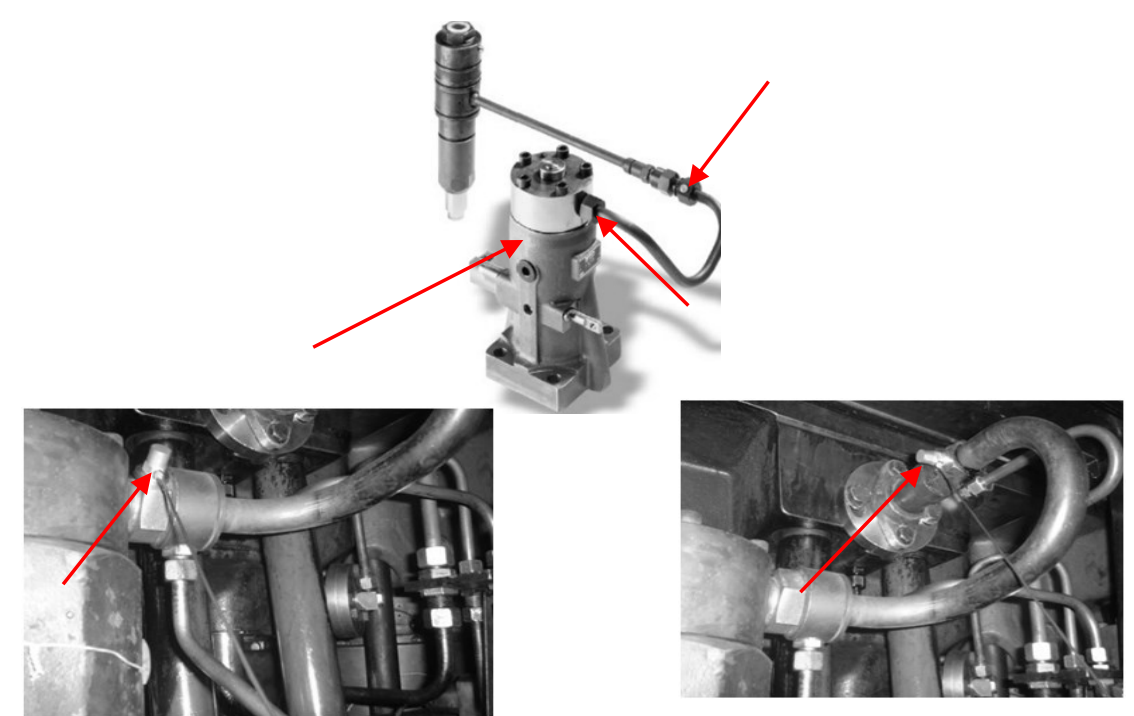

Fig. 1. Experimentally chosen (indicated by arrows) places for the mounting of an AE sensor Source: (Bejger 2012).

Acoustic emission in this case may come from processes associated with the displacement, fatigue fractures, phenomena related to the loss of material integrity, cavitation, tribological processes, flow of a medium (e.g. fuel) etc. AE is detected when elastic waves, generated by the said phenomena, reach the $A E$ sensor surface. The main assumption of the tests related to the detection of changes in the components of the injection system is that every disturbance of the work of system elements corresponds to a change in the AE signal frequency of the signal emitted by the system. The AE signal has characteristic frequencies different from those emitted by a correctly working system - in most cases the band of 'characteristic frequencies' changes.

\section{THE ALGORITHM OF METHODS FOR DIAGNOSING MARINE ENGINE INJECTION SYSTEMS BY USING AE ELASTIC WAVES}

Figure 2 presents an algorithm of the methods developed for diagnosing marine engine injection systems (both two and four-stroke) using the AE signal (Bejger 2012). Based on multi-year experience in the diagnosis of machines, the authors propose an analysis of the source signal from a process by three independent methods. Depending on the needs, it is possible to detect both a specific fault of a system (element) or only to determine whether the system work is correct or defective. 
Proposed below are descriptors of AE signal characteristics in the frequency domain in the form of: wavelet analysis, amplitude of spectral density and authors' new method using the frequency distribution at a given instant.

The wavelet analysis can be used for an analysis of non-stationary signals that occur in the process of fuel injection (operation of injection equipment elements). In the case herein considered the continuous wavelet transform using the Morlet wavelet (Suzuki and all, 1996) was applied, described by the formula (1):

$$
\psi(t)=C e^{-x^{2} / 2} \cos (5 x)
$$

The coefficients representing the analysed signal in the time-frequency domain are described by the relationship (2):

$$
C_{f}(a, b)=\left(f * \Psi_{a, b}\right)=\int_{-\infty}^{\infty} f(t) \cdot \Psi_{a, b}(t) d t
$$

In the Morlet analysis, the number of wavelet oscillations is constant, and frequency change is accompanied by a change in wavelet time range. The variable time range of wavelet analysis results, consequently, in variable time precision of localising particular frequency components of the signal. Therefore, more precise time-related localisation can be made for high frequencies (occurring in the AE elastic wave).

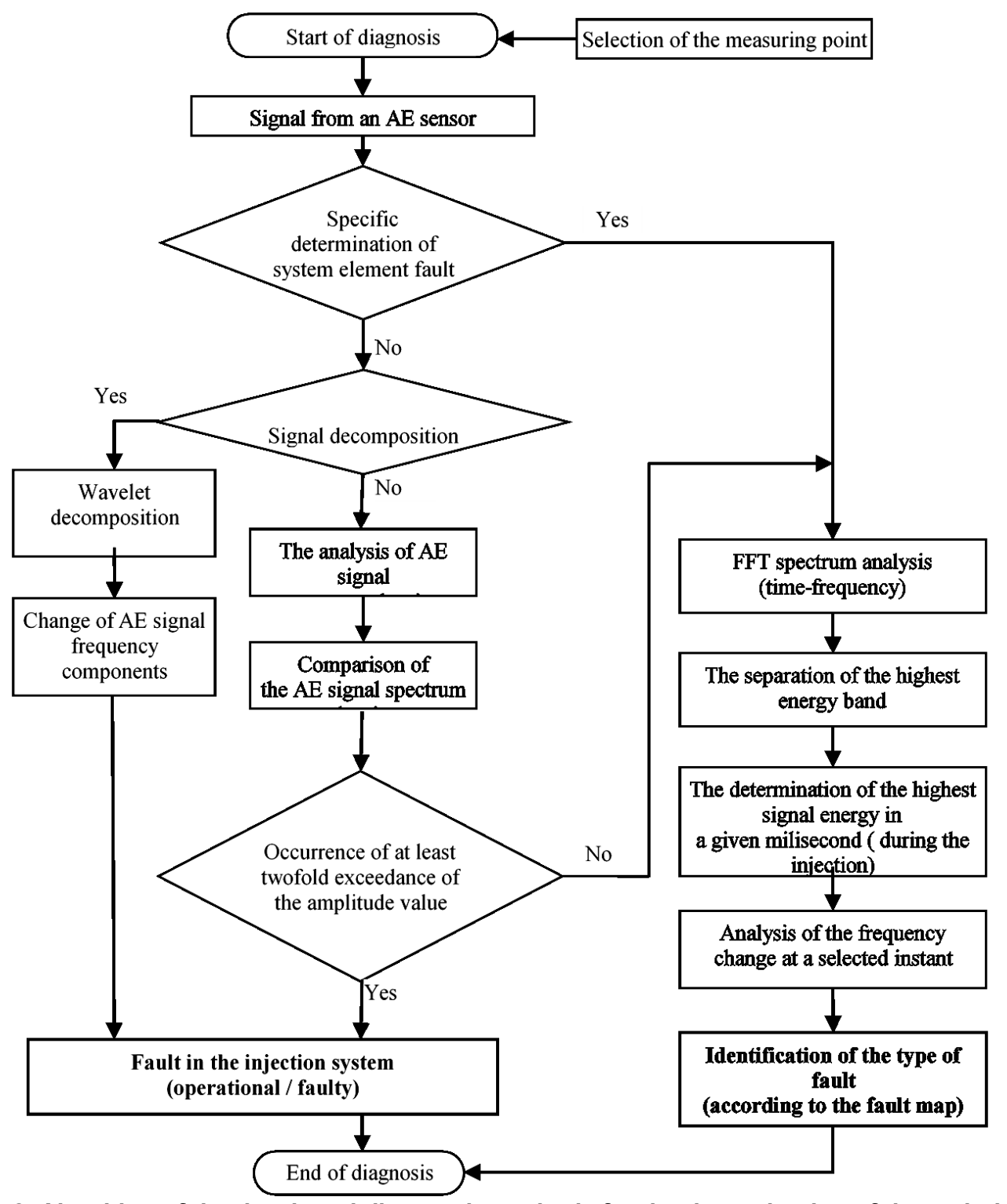

Fig. 2. Algorithm of the developed diagnostic methods for the determination of the technical Source: (Bejger 2012) condition of the injection system of a diesel engine 
The processing results are shown in Figure 3, where the signal energy component generated by a fault (torn off atomizer nose) is visible in the form of wavelet coefficients (function of scale and location) prolonged in time, with decreased frequency and values distributed on the timescale plane. The presented method allows observing the changes of the looked-for symptom. The low scale in the diagram indicates that we are dealing with the coefficients corresponding to high frequencies, that is local characteristics of the signal (e.g. disturbances). The high scale characterizes low frequencies, that is global characteristics of the signal (e.g. periodicity/uniformity of the process). Disturbances are a local characteristic. By removing the coefficients of the so-called "short" wavelets we can filter the signal into the form of the signal coming from the examined process.
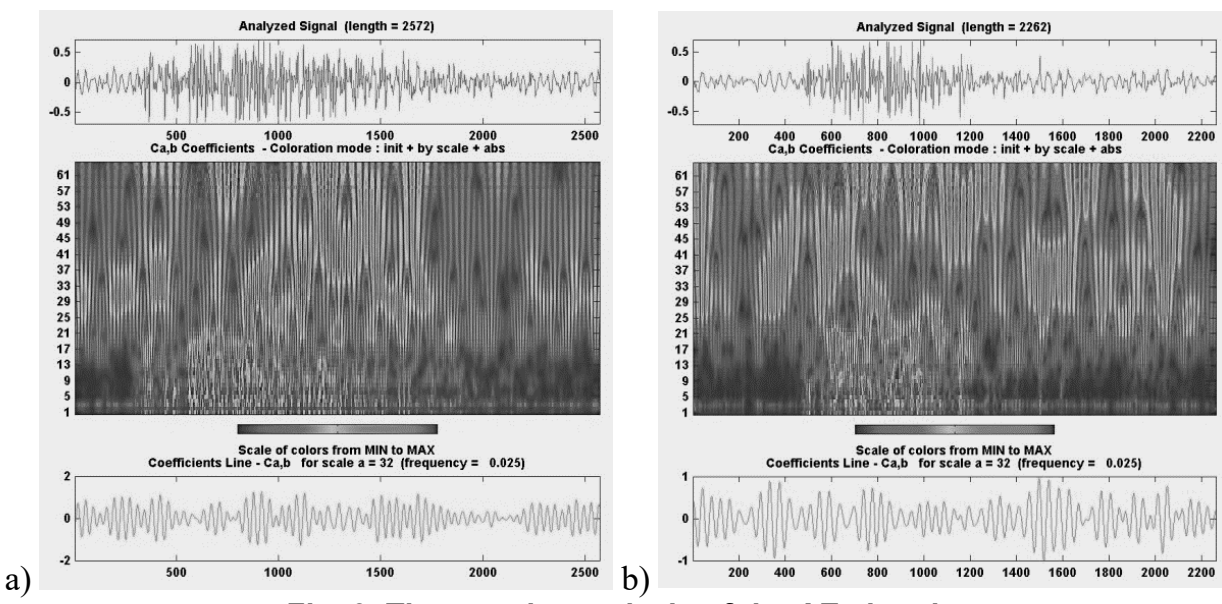

Fig. 3. The wavelet analysis of the AE signal:

Source: (Bejger, 2012)

a) properly working injector, b) damaged injector, with a torn off atomizer nose

If follows from the authors' research that the graphic interpretation of the spectral density of $A E$ elastic wave signal is a relatively fast comparative method for finding out if a fuel injector is defective or not.

The spectral density of the signal in time $T$ determines a mean signal power per frequency in time $T(3)$ :

$$
G_{T}(f)=\lim _{B \rightarrow 0} \frac{x_{r m s, T}^{2}}{B} \quad \text { or } \quad G_{T, B}=\frac{x_{r m s, T}^{2}}{B}
$$

where:

$B$ is a frequency of a filter band $\mathrm{Hz}$.

It has been demonstrated (Bejger, 2012; Mazuruk, 2013, Saban Ulus \& Selcuk Erkaya 2016), that the values of this amplitude permit for a bi-state (good - bad) estimation of the injector system technical condition. Based on performed tests it has been also shown that when the limit condition value of injector system fault condition is exceeded, there is at least twofold increase in the amplitude of spectral density of the signal (Fig. 4-5).

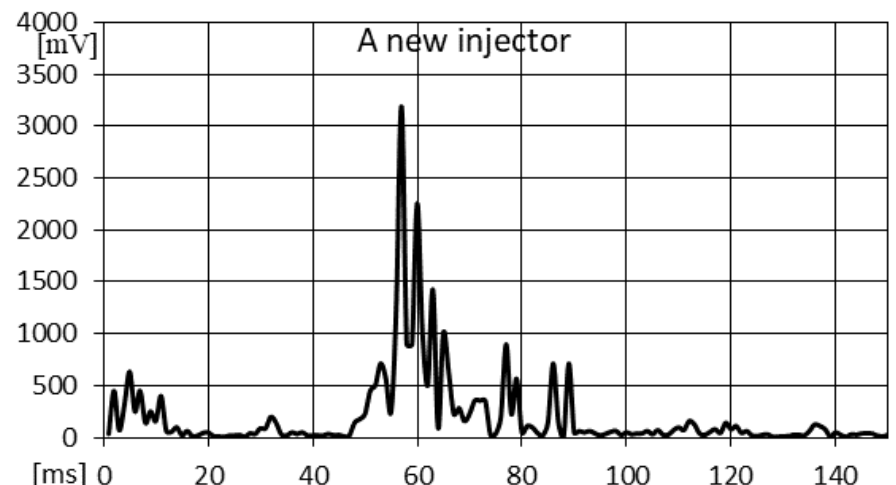

Fig. 4. Amplitude of spectral density for a new injector

Source: (Bejger, Drzewieniecki, 2015) 


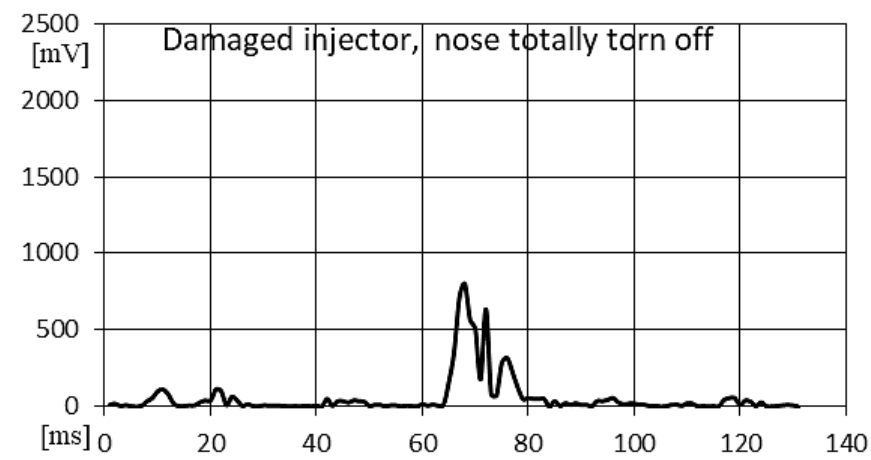

Fig. 5. Amplitude of spectral density for an injector with a broken nose (visible in Figure 6) Source: (Bejger, Drzewieniecki, 2015)

In relation to smaller marine engines, this method proves perfect for the identification of such faults as atomizer nose damage (Figure 6), or fuel pipe fracture. This measure is used by the authors in practical diagnosis of marine engines in case there is no need to identify which specific element is damaged and it is sufficient to find out the bistate reliability measure, i.e. whether the system is good or bad. However, the basic disadvantage of such a procedure is the need to determine in advance the value of spectral density amplitude from a correctly working injector and injection pump.
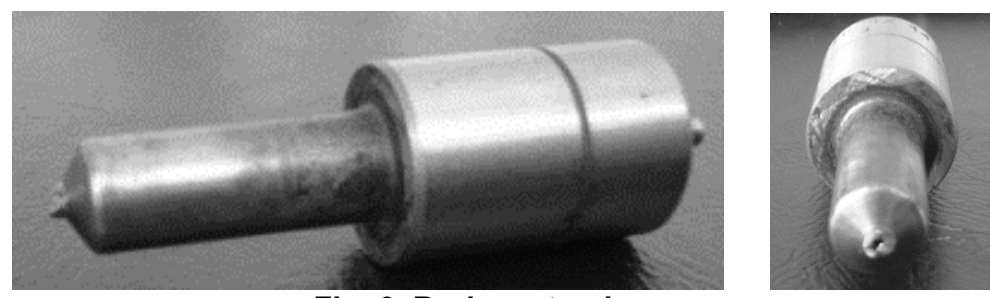

Fig. 6. Broken atomizer nose

Developed at the Maritime University of Szczecin, the method for diagnosing injection systems of diesel engines makes it possible to identify a specific element that causes the fault (Bejger 2012). Based on the multi-year research performed on different types of engines it has been shown that for a correctly working injector, the frequency change in a specific millisecond (the time instant at which during injection the AE signal energy is the highest), Figure 7, circular mark) is taking place uniformly (as in Figure 8 ) - first increasing, then decreasing. It reaches its maximum at a frequency from $8 \mathrm{kHz}$ to $14 \mathrm{kHz}$ for low power engines and from $8 \mathrm{kHz}$ to $16 \mathrm{kHz}$ for medium power engines. This can be explained by analysing the change of $A E$ signal energy during the fuel flow from the atomizer. This change, corresponding to obtained signal increase or decrease, is due to altering under-needle pressure (depending on the extent of the needle opening during injection).

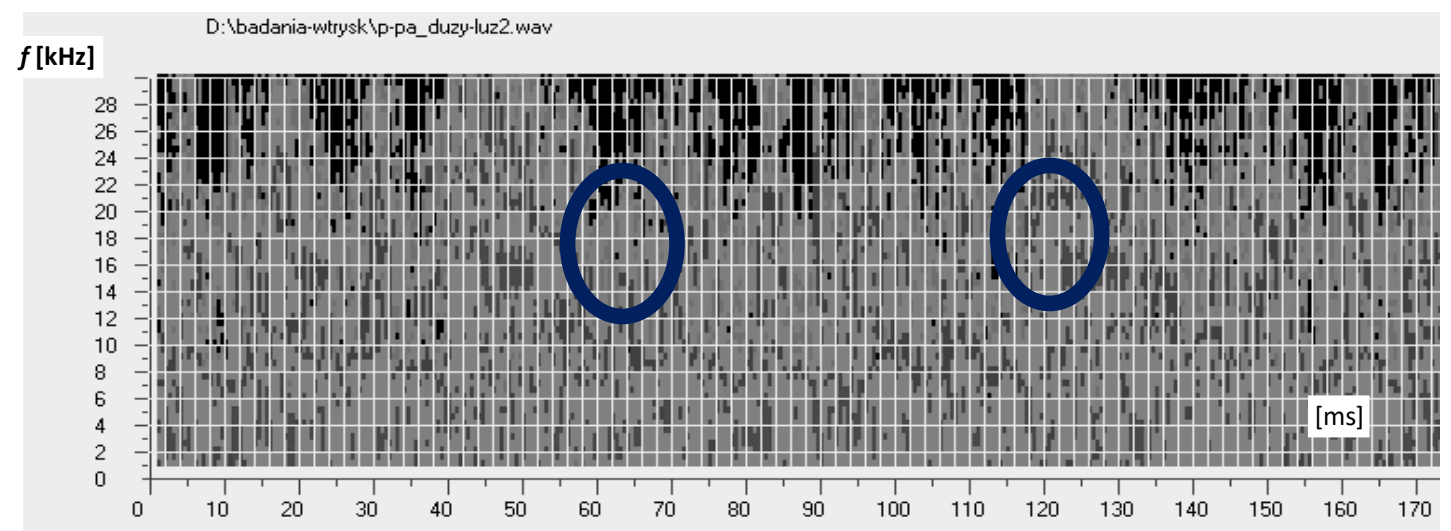

Fig. 7. Time-frequency analysis of the fuel injection process in a working engine 
In the case of turbulent outflow of fuel through the atomizer holes, for instance when the injector is partly coked, there will also be a disturbance affecting the frequency of AE elastic wave signal (Fig. 8).

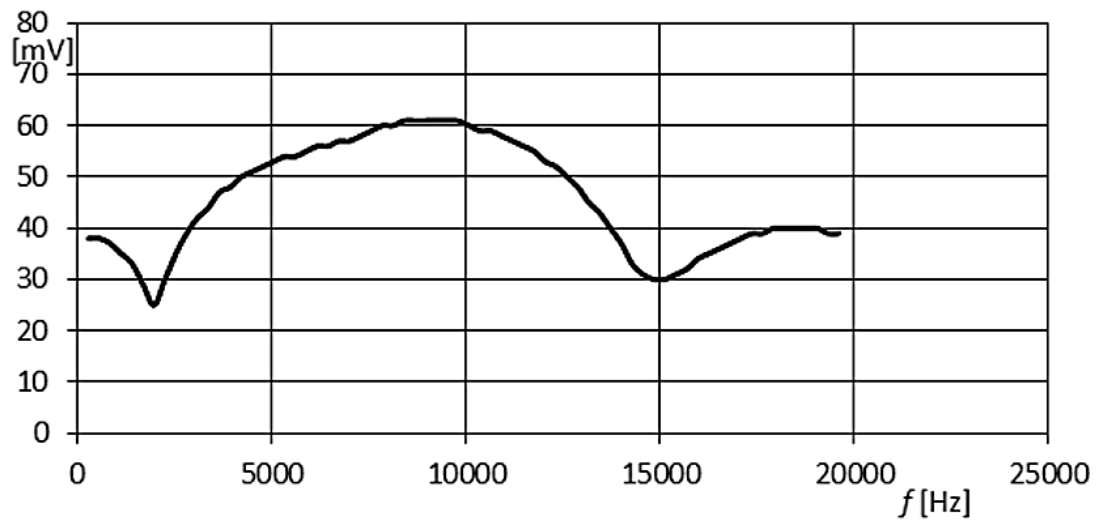

Fig. 8. A change in AE signal frequency at an instant when the AE signal energy is the highest

In each case, the coked injector causes a sudden drop of frequency in the form of a downward peak (Figure 9).
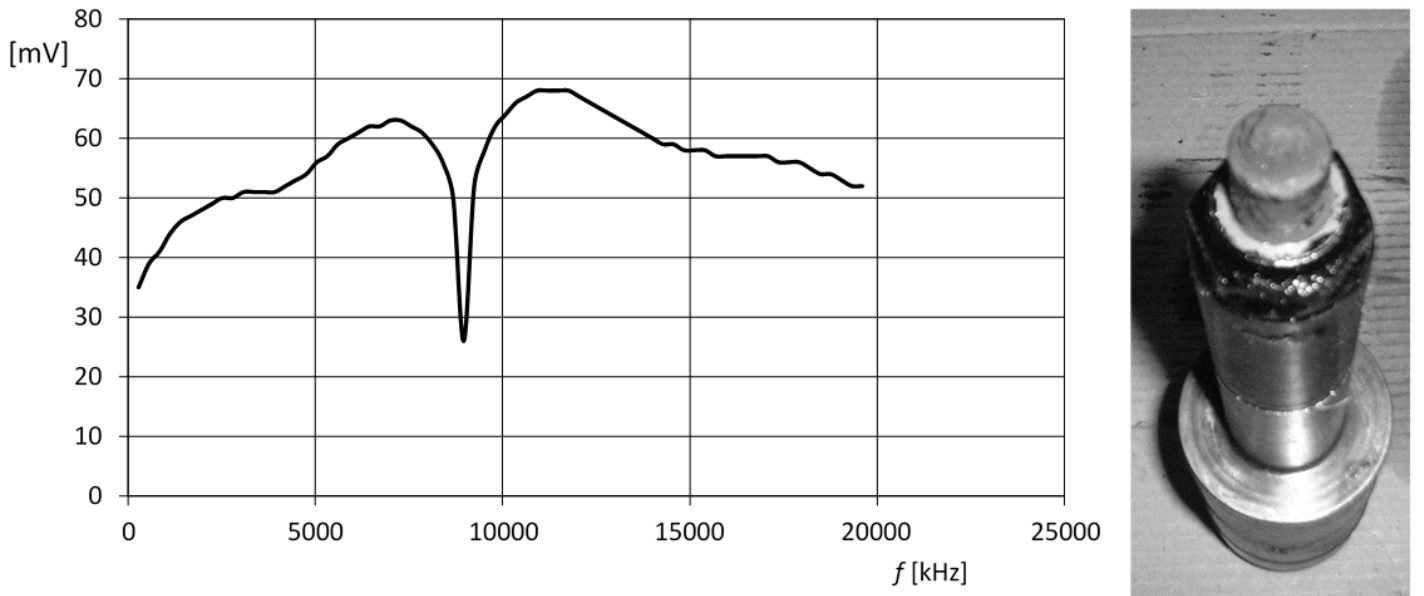

Fig. 9. The frequencies of $A E$ signal - left and coked injector image - right (Wärtsilä SW 380 engine, 3960 kW)

\section{CONCLUSION}

Early detection of a fault leads to more economical operation and reduced emissions of pollutants contained in exhaust gases from engines. The use of $A E$ elastic waves provides a method that does not require additional sensors to be installed, e.g. on a high pressure injection tube. It is a non-invasive diagnostic method that indicates early condition of damage to injection systems. Furthermore, the authors have shown that the amplitude of spectral density of $\mathrm{AE}$ signal can be used as a fast method of a bi-state identification of a fault.

\section{REFERENCES}

Bejger A. (2012). Zastosowanie fal sprężystych emisji akustycznej do diagnozowania układów wtryskowych okrętowych silników spalinowych. FOTOBIT, Kraków.

Holroyd T. (2000). Machine \& Systems Condition Monitoring Series. Acoustic Emission \& Ultrasonics, Coxmoor Publishing Company's, Oxford UK.

Goldman S. (1999). Vibration Spectrum Analysis. A Practical Approach. Industrial Press Inc. New York.

Lalanne Ch. (2009). Random Vibration, John Wiley \& Sons, Inc. ISTE Ltd.

Suzuki H., Kinjo T., Hayashi Y., Takemoto M., Ono K., Appendix by Hayashi Y.(1996). Wavelet Transform of Acoustic Emission Signals", Journal of Acoustic Emission, Vol. 14, No.2 (1996, April-June), pp. 69-84. 
Bejger A., Drzewieniecki J. (2015). Analysis of tribological processes occurring in precision pairs based on example of fuel injection pumps of marine diesel engines, Scientific Journals Maritime University of Szczecin, 4 (113).

Chybowski L., Gawdzińska K. (2016). On the Possibilities of Applying the AHP Method to a Multi-criteria Component Importance Analysis of Complex Technical Objects. Advances in Intelligent Systems and Computing, Volume 445, Springer International Publishing, pp. 701-710 [ISSN 2194-5357, ISBN 978-3-31306-1, online ISBN 978-3-319-31307-8, DOI 10.1007/978-3-319-31307-8_71].

Wik C. (2010). Reducing medium-speed engine emissions. Journal of Marine Engineering \& Technology, 9:2, p. 37-44.

Chandroth G. (2014). Condition monitoring: the case for integrating data from independent sources. Journal of Marine Engineering \& Technology, 3:1, p. 9-16.

Saban Ulus and Selcuk Erkaya (2016). An Experimental Study on Gear Diagnosis by Using Acoustic Emission Technique. International Journal of Acoustics and Vibration, Vol. 21, No. 1. pp 103-111. http://dx.doi.org/10.20855/ijav.2016.21.1400.

Pawełczyk M., Wrona S. (2016). Impact of boundary conditions on shaping frequency response of a vibrating plate - modelling, optimization, and simulation. Procedia Computer Science. Vol. 80. pp. 1170-1179. doi: 10.1016/j.procs.2016.05.450

Deja A. (2013). Organisation of the reception of ship-generated wastes and cargo residues illustrated by selected examples of European Union seaports. Scientific Journals Maritime University of Szczecin, 33 (105) pp.16-2.

Bejger A., Chybowski L., Gawdzińska K. (2018). Utilising elastic waves of acoustic emission to assess the condition of spray nozzles in a marine diesel engine, Journal of Marine Engineering \& Technology, Volume 17, - Issue 3, https://doi.org/10.1080/20464177.2018.1492361

Mazuruk P. (2013). Diagnostyka zasobnikowych układów paliwowych na podstawie fazowości procesu wtrysku. Rozprawa doktorska, Wydział Mechaniczny - Akademia Morska w Szczecinie.

Bejger A. - Patent 1 PL P.398743 Sposób i układ do diagnozowania układu wtryskowego silników o zapłonie samoczynnym, zwłaszcza okrętowych (Polish Patent).

Bejger - Patent 2 EU 13460015.4-1606 A method and a system for diagnosing injection systems of self-ignition engines, particularly marine engines.

ASTM E1316 - 16 Standard Terminology for Non-destructive Examinations

Wavelet Toolbox For Use With Matlab. 